\title{
Supervision of master theses based on Scrum: A case study
}

\author{
Gonçalo Tomás $^{1} \cdot$ Miguel Mira da Silva ${ }^{1}$ (D) José Bidarra ${ }^{2}$
}

Received: 20 September 2020 / Accepted: 3 January 2021/Published online: 22 January 2021

(C) The Author(s), under exclusive licence to Springer Science+Business Media, LLC part of Springer Nature 2021

\begin{abstract}
The success rate of a master program on Information Systems and Computer Engineering (MEIC) in a Portuguese university is very unsatisfactory, showing that less than half of the students complete the assigned work in their first term. However, the success rate of a group of students that were supervised based on the Scrum framework was much higher. So, in this study we assess the current situation and identify the benefits of using Scrum to manage master's theses. Evidence suggests that this approach increases the number of students successfully completing their projects. So, this paper discusses the issues at stake and reports on a qualitative study with focus on the actual practices and benefits reported by students in the master program. We found that some methods in the Scrum framework can address existing problems in the development of theses with very positive results.
\end{abstract}

Keywords Scrum $\cdot$ Master program $\cdot$ Management of theses $\cdot$ Success rate

\section{Introduction}

The underlying basis for this study is the challenge of almost every master's program that ends with the submission of a thesis. This represents for the student a hard challenge in terms of academic work, and for the majority of students it will be the first-time doing work of such a demanding nature. So, in this study, we propose to

Miguel Mira da Silva

mms@tecnico.ulisboa.pt

Gonçalo Tomás

goncalotomas@tecnico.ulisboa.pt

José Bidarra

bidarra@uab.pt

1 Instituto Superior Técnico, Universidade de Lisboa, Av. Rovisco Pais, 1000 Lisbon, Portugal

2 Universidade Aberta, Rua da Escola Politécnica 147, 1269 Lisbon, Portugal 
investigate the actual advantages of using the Scrum Framework during the supervision process. More specifically, we aim to find out which parts of the Scrum framework may benefit the supervision of master theses, based on qualitative data collected in a specific program. Scrum methods have been used with success in the industrial development of computer software, but not so much in the educational area. However, there is potential for using Scrum to help students to learn more effectively and develop themselves in an enjoyable way. Scrum as a framework is able to specify roles, artefacts and events that give both the student and the teacher the structure which is normally missing within project-based learning. We think that Scrum may be used by students as an engaging and self-organizing way to work collaboratively and dynamically, and this may improve mutual collaboration and reflection among students and teacher. Experiences of students during project-based learning are described by DinisCarvalho et al. (2018) which showed that students recognized the advantages of the Scrum methodology and scored above average compared to students using regular teaching approaches.

Within the master program in Information Systems and Computer Engineering (MEIC) of Instituto Superior Técnico (IST), the success rate (or completion rate) of a master's thesis assignment, that is, the percentage of students approved in the first enrolment has been increasing. For example, in the 2012/2013 academic year, the percentage of students' approval in the first enrolment of the master's thesis assignment in one of the campuses was just $30 \%$, while in the $2015 / 2016$ academic year the percentage on the same campus was $55 \%$, which represents an improvement but still an unsatisfactory value.

Since the 2012/2013 academic year, studies and inquiries have been performed by the Statistics and Prospective Unit (NEP) ${ }^{1}$ to determinate the reasons for the existence of very unsatisfactory completion rates and the longer (than stipulated) average time of theses completion. In these studies, several students were interviewed to ascertain their satisfaction with the process of supervision and development of master's theses. In the case of the MEIC, the students who rated their orientation as unsatisfactory pointed out as main reasons: lack of commitment and limited time of the supervision team to monitor the work, insufficient knowledge transmission ability, and lack of support for experimental and field work.

According to Hans (2017) and Kudikyala and Dulhare (2015), the quality of the final products of students' projects has by and large been declining. Furthermore, they found that the student's poorly completed projects were not delivered at all on the due dates. These authors also added that the use of Scrum could be a reliable strategy to ensure that projects would be carried out in an iterative manner, preventing students to wait for the final moment to work on them. This strategy would follow the general approach used in the application of the Scrum framework in software development projects. However, this raises some questions: is the Scrum project management really applicable to academic research theses? Does Scrum facilitate the work of a student towards completing a master thesis?

To achieve our aims, we set out an exploratory case study at IST, with focus on the perceptions and results related to Scrum project management methods, traditionally

\footnotetext{
${ }^{1}$ Studies regarding the success rates of master theses can be found at http:/quc.tecnico.ulisboa.pt/en/ dissertacoes/
} 
applied to software development, but in this case used for managing thesis development and supervision. A group of second cycle students, crossing a few years, was managed based on the Scrum framework, and the main goal was to collect their opinions, experiences and results regarding the application of the methods. For data collection, we used semi-structured interviews that were analyzed with the NVivo 12 qualitative data analysis software, in order to understand which practices of Scrum and agile methodologies were more effective, and if these practices were related to the success of each thesis project.

\section{The Scrum framework}

The well-known Scrum framework (Fig. 1) is proposed as a more effective and agile way to develop software projects (Sutherland and Schwaber 2017). This was set out as an alternative to methodologies such as Waterfall, where a project is planned in the beginning and completed in different stages until it is released to customers. These methodologies have disadvantages and most of the time the clients never receive the product that they really wanted.

Scrum is based on a powerful idea: when you start a project, why not regularly check in, see if what you're doing is heading in the right direction, and if it is actually what people want? (Sutherland 2014). Scrum is also supported on empirical processes, that is, it is based on the assumption that it is difficult to predict and plan a project from the beginning to the end. The basic approach used in Scrum, to plan and manage work in progress, is supported by iterations lasting between two and four weeks. These iterations are known as "Sprints", and that's where the work is developed and where the meetings associated with Scrum take place. Each Sprint integrates a process that allows for the development of work in an iterative and incremental way until a product is ready to be delivered. When a Sprint ends, the following Sprint begins immediately.

In order to plan and manage work with Scrum it is very common to use a Product and Sprint Backlog. The Product Backlog is a list that contains everything that needs to be done in a project life cycle. At the beginning of a project, this list does not need to be complete. Over time the Product Backlog grows and changes as stakeholders learn

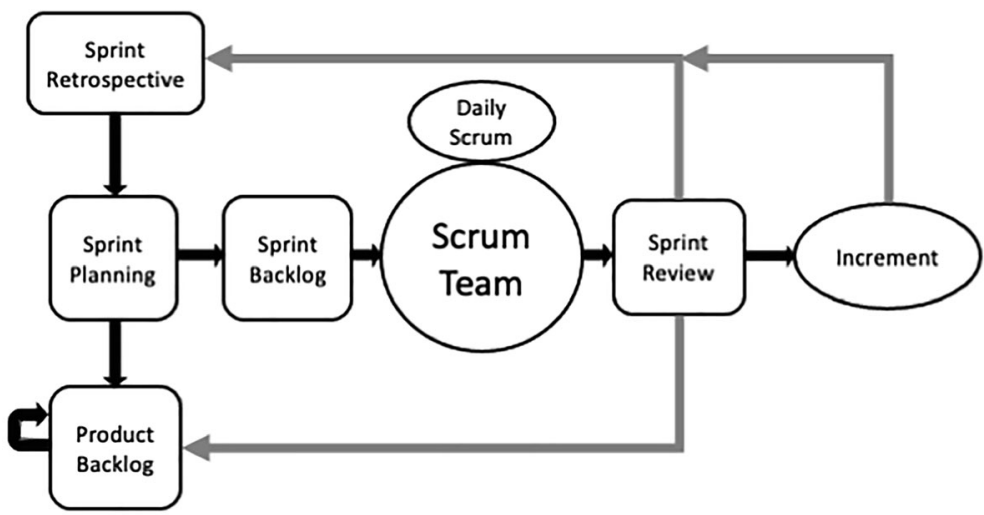

Fig. 1 Scrum framework, based on (Sutherland and Schwaber 2017) 
more about the project. Sprint Backlog is constituted by some items selected from the Product Backlog to be done in a Sprint.

In the context of Sprints, there are several meetings. A Sprint Planning meeting can be divided into two parts, one part where it is discussed what can be done in a Sprint and another where the work to be performed is planned and discussed. This meeting represents the beginning of a Sprint cycle. The Sprint Review meeting is where the work done in a Sprint is reviewed, taking into account what was inserted in the Sprint Backlog, to understand if the planned work has been done and if any work increment has to be applied in the next sprint. In this meeting the Product Backlog is also updated thus setting the priority of the items in the list. The Sprint Retrospective meeting is where the Scrum Team discusses what went well or wrong, in order to find improvements to apply in the next Sprint. The meetings generally occur separately, but the Sprint Review and Retrospective meetings may occur on the same day, signaling the end of a Sprint cycle. These meetings have potential for use in academic projects (Broman 2015), for instance, each student should answer three basic questions: i) what have you done the last week, ii) what do you plan to do the coming week, and iii) do you have any problems? The purpose of the meeting is that the supervisor can react to the responses and plan a more detailed on-demand supervision meeting with specific students.

So, typically Scrum focus on project management and can be used as a mechanism to handle complex projects with unpredictable results, whenever the scope of a project may be undefined, and to minimize the risks associated with the development. Therefore, Scrum can help address uncertainty, and respond to changes, by providing a set of rules and guidelines to be more productive (Sutherland and Schwaber 2017). Previous experiences with Scrum in student projects were predominantly successful, an example is the research conducted by Rover et al. (2014), a case study on a capstone design project where agile project management was used, with Sprints and meetings held with the students. According to Rover et al. (2014), Sprints and meetings fostered communication processes that originated frequent feedback and established what items and added value could be made in Sprints. The major outcomes or benefits originated by these agile practices according to the authors were: teamwork, product quality, customer focus, and iterative development.

Mahnic and Rozanc (2012) designed a course to teach how Scrum could be used in generic real-world environments, in order to help students understand the issues and to improve skills regarding the utilization of Scrum methods. They reported that a capstone course is a suitable place for the introduction of this method and to simulate a real-world experience. These researchers presented the results of a survey made in an academic context, and another in an industrial context, to evaluate what Scrum practices students perceive as more important for the success of software projects, compared with the opinions of professional developers, in order to understand similarities and differences of both parties' perspectives.

Hicks and Foster (2010) discuss the application of an agile research group management method called SCORE (SCrum fOr REsearch), an adaptation of Scrum used to advise and work with PhD students. They decided to implement this adaptation of Scrum as their commitments and number of students increased, and therefore the number of meetings also increased, thus affecting the quality of 
the supervision. The main issue arising from this situation was the slow response to difficulties occurring in students' research. The two key elements of SCORE described by Hicks \& Foster are "three-times-per-week status meetings" and "on demand one-on-one meetings". In status meetings everyone exposed what they were doing since the last meeting and what results were obtained, namely if they found any issues, and then decide what to do next. To discuss more complex ideas, or problems that emerged on status meetings, or when someone needed more time to discuss specific topics, they would hold "on-demand meetings", which the authors describe as the removal of obstacles commonly presented by students.

The research by Mariz et al. (2010), investigating the successful relationship between the projects that use Scrum and the use of agile practices, was implemented in an industrial context since the focus was on the development of software projects. Twenty-five agile practices were evaluated to understand which practices were more related to the success of projects, a perspective that we also followed. In another study, Solinski and Petersen (2016) report on the significant benefits that originate in the adoption of agile practices and indicate which ones are commonly used. Following the same approach, Begel and Nagappan (2007) conducted a research on agile development in an industrial context. They asked the participants which agile practices they used in their work and what were the top three benefits of agile in order to form a ranking of common benefits.

However, we could not find research specifically addressing the supervision of academic theses based on Scrum. Mostly there is a considerable number of articles about the use of Scrum, and the adoption of agile practices and their relation to the success, concerning specific non-academic projects. This triggered the motivation to gather more data on the possibility of using Scrum for a more effective academic thesis development, following-up on its success in industrial software development.

\section{Research methodology}

The research framework chosen to guide our research was the Case Study Research Methodology (CSRM), defined by Yin (2017) as an 'empirical inquiry that investigates a contemporary phenomenon within its real-life context'. This approach was chosen to make the best of the experience held by the participants in an authentic academic context, and profit from their understanding of the adoption of Scrum in the development of a master's thesis. It was essential for us to draw conclusions about the use of this project management method in alleviating the known issues leading to student dropout and failure in a specific institution (IST) and within a specific context (MEIC).

The case study methodology is characterized by the examination of several variables so experimental controls are not required (Benbasat et al. 1987), but it requires that the behavior of the participants is not manipulated (Baxter and Jack 2008). So, the perspective we followed may be described as a qualitative and exploratory case study without the need for a quantitative analysis. 
The six steps proposed by Yin (2017) were followed:

(1) Determine and define the research question(s): Identification of the research question, determinate the purpose of the study and also the planning of it.

(2) Select the case(s) and determine data gathering and analyses techniques: The researcher must determine the unit of analysis of the study, that is, selecting between single and multiple case study. To select the unit of analysis, the researcher can review the purpose of the study, which cases can provide information to answer the research questions. Regarding the information, the research must choose in advance how this will be gathered and analyzed.

(3) Prepare to collect data: Develop interview guidelines to ensure that the questions asked are the same to all participants and make a template mail communication to invite the participants.

(4) Collect data in the field: The researcher collects data from multiple sources to answer the research question(s).

(5) Evaluate and analyze the data: After finishing collecting the required information, depending on the type of data gathered and the techniques chosen previously, the researcher explores the data collected to find evidence to answer the original research question(s).

(6) Prepare the report: Once the case study is completed, the researcher documents, shares and communicates his or her findings.

Considering the difficulties in finding similar research in the literature review, a special motivation to use this methodology was the fact that there is insufficient information regarding the adoption of Scrum in the academic context, namely, for development, supervision and delivery of master theses. Clearly there are too many variables involved in a case study, so we wanted to start somewhere and get some insight concerning the data we had collected for some years. According to Runeson and Höst (2009), the use of CSRM is appropriate whenever there are too many variables and a high degree of uncertainty, since this methodology is suitable to 'find out what is happening, and seeking new insights'.

\subsection{Research question}

Bearing in mind that the main reason for starting this study was the unsatisfactory completion rates of master theses, our dominant research question thus becomes:

\section{- Does Scrum benefits students in successfully completing their master theses?}

Furthermore, we also wanted to assess which good practices of the agile methodologies were recognized by each student during the development of a master thesis, and their contribution to the success of a project, considering the track record of agile methodologies and Scrum in other contexts.

\subsection{Data gathering}

In order to evaluate the effects of the Scrum methodology in guiding and managing students during the development of their master theses, we collected our data from 
students who were, or had been, supervised by means of a subset of agile methods over the years. Their experience and insights were key to draw conclusions about the potential use of the Scrum framework in the specific academic context. For this purpose, fifty-six students from nine academic years were interviewed (Table 1). This contemplated a time frame spanning from 2009 to 2018.

\subsection{Research tools}

The main data gathering tool used in this study was the guided interview. This enabled the collection of data in order to 'provide in-depth information pertaining to participants' experiences and viewpoints of a particular topic' (Turner III 2010). Overall, the main argument was that 'Case Studies tend mostly to be based on qualitative data, as these provide a richer and deeper description' (Runeson and Höst 2009).

Interviews with students could be categorized as "single interviews" or "group interviews", enabling the interviewer to approach arising topics, namely through follow-up questions seeking clear answers and underlying reasons. So, semistructured interviews were used, which are the type most often used in qualitative research. In these semi-structured interviews we followed guidelines with prepared topics and specific questions, but the questions were also adjusted to the answers provided by the interviewee, so the sequence and the flow of the conversation was rather flexible. This allowed for the exploration of other topics and questions that were raised during the sessions (Robson and McCartan 2016), and also enabled follow-up questions to get more meaningful replies.

The interview guidelines used were based on documented research on the experience and practice of Scrum in other contexts (Hicks and Foster 2010; Overhage et al. 2011). The following questions were used in our study:

(1) Did you already know about the Scrum framework before you started the thesis?

(2) How was Scrum applied and used during the development of your master's thesis?

Table 1 Number of students interviewed by academic year

\begin{tabular}{ll}
\hline Academic year & Number of students \\
\hline $2009 / 2010$ & 4 \\
$2010 / 2011$ & 5 \\
$2011 / 2012$ & 5 \\
$2012 / 2013$ & 5 \\
$2013 / 2014$ & 6 \\
$2014 / 2015$ & 6 \\
$2015 / 2016$ & 2 \\
$2016 / 2017$ & 10 \\
$2017 / 2018$ & 13 \\
\hline
\end{tabular}


(3) What benefits do you think Scrum can bring to the management process and development of a master's thesis?

(4) What are the issues/inconveniences that may result from using Scrum during the development of a master's thesis?

(5) Regarding Scrum elements/artifacts (Product Backlog, Sprint Backlog, Sprint, Sprint Planning Meeting, Sprint Review Meeting, Sprint Retrospective Meeting, Product Owner, Scrum Master, Team) which do you think had the greatest value for the development of the thesis and why?

(6) If meetings (Scrum meetings) were held during the development of your thesis, how were they held? What was done at the meetings?

(7) Regarding the use of Scrum in theses, in addition to the elements already mentioned (as being most important), can you identify the importance of other elements in this particular case?

(8) Do you have any suggestions for improving the method used? If so, which ones?

(9) What are the drawbacks of this method for the development of your thesis?

The interviews were made via Skype or face-to-face, depending on the preference of each interviewee. In each case the students were asked for permission to make an audio recording. During the interview notes were also taken and afterwards a transcript of the interview was created. Full anonymity was assured throughout the process.

The data collection activities produced large amounts of textual data in the form of transcripts and field notes. The systematic and careful preparation and analysis of the data was very time consuming so the NVivo 12 software was used to lessen the burden somehow. NVivo features, such as character-based coding, rich text capabilities and multimedia functions were invaluable for data management (Fig. 2). The objective was to provide evidence-based implications and extract relevant conclusions based on the interviews.

\section{Empirical study}

Based on a preliminary exploration, we knew that the success rates of students who were supervised and managed based on Scrum practices was very high compared to the global rates presented in the studies done by NEP. In Table 2 we show the number of students enrolled in the master's thesis stage at the two IST campuses, the completion rates of the students who finished their master's thesis at the first enrolment, and the completion rate of students that were supervised with the guidance of Scrum-based methods.

Soon we realized that more (qualitative) information was needed to help us understand the factors behind the success. In this case the main objective was to derive conclusions from the qualitative data while keeping a clear chain of evidence. Therefore, the value of the data and opinions obtained from the interviewees. Since the information in the transcripts was textual and the number of interviews was rather large, we decided to use the NVivo software to help us in the coding process, that is, we assigned sections of text or testimonials in categories that derived from the emerging topics in the interviews (Hilal and Alabri 2013). To expose a chain of evidence, this process permitted the grouping of quotes and the discovery of patterns, since coding 


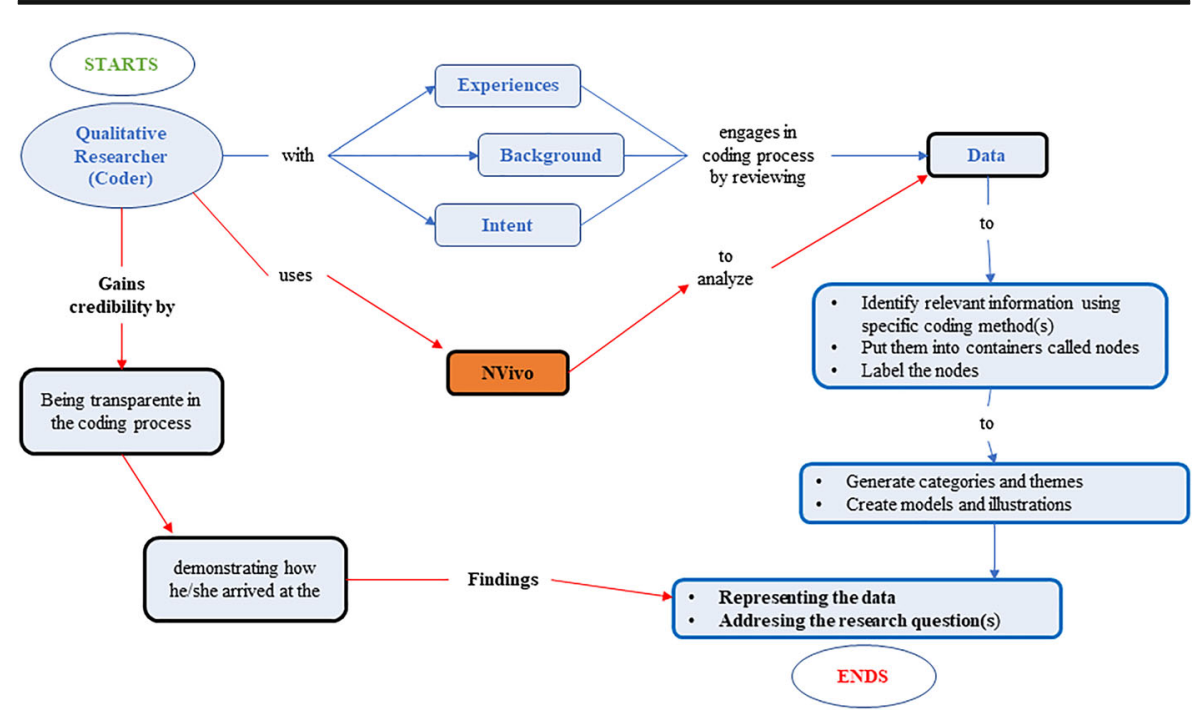

Fig. 2 Stages of qualitative data analysis with NVivo based on (Adu 2016)

allowed the gathering of all the raw text about a topic in one place and made it easier to see patterns and contradictions. In Fig. 3 we represent the process that was followed in our data treatment endeavor. However, in this analysis provisional codes were not used. Provisional codes 'can be developed from anticipated categories or types of responses / actions that may arise in the data yet to be collected' (Saldaña 2015). The code tree and its codes were created on-the-fly while analyzing the transcripts of interviews in order to gather all the references pertaining to a specific topic or theme. The emerging topics were closely related to the questions in the interview script (presented in subsection 3.3).

The transcripts were coded by only one researcher, but all the findings and results were always available to the other researchers in order to obtain feedback from them and discuss the progress of the coding process and enable the analysis. Discussion about the data gathered is an important aspect, according to Saldaña (2015) it 'provides

Table 2 Information about the number of students enrolled in the master's thesis and the success rates in four academic years

\begin{tabular}{|c|c|c|c|c|c|}
\hline & \multicolumn{5}{|c|}{ Academic Year } \\
\hline & $2012 / 13$ & 2013/14 & $2014 / 15$ & $2015 / 16$ & $2016 / 17$ \\
\hline $\begin{array}{l}\text { Number of Students enrolled in Master Thesis } \\
\text { (Campus Alameda) }\end{array}$ & 116 & 110 & 148 & 151 & 146 \\
\hline Success Rate (Campus Alameda) & $30 \%$ & $48 \%$ & $43 \%$ & $55 \%$ & $49 \%$ \\
\hline $\begin{array}{l}\text { Number of Students enrolled in Master Thesis } \\
\text { (Campus Taguspark) }\end{array}$ & 79 & 80 & 94 & 90 & 98 \\
\hline Success Rate (Campus Taguspark) & $32 \%$ & $48 \%$ & $41 \%$ & $54 \%$ & $29 \%$ \\
\hline Success Rate of Students Managed with Scrum & $100 \%$ & $80 \%$ & $100 \%$ & $100 \%$ & $90 \%$ \\
\hline
\end{tabular}


not only an opportunity to articulate your internal thinking processes, but also presents windows of opportunity for clarifying your emergent ideas and possibly, making new insights about the data'.

The codes assigned to the data collected were Backlog, Planning, Review, Retrospective and Sprints. These five codes were child codes/nodes of a super code denominated Scrum. Another choice of hierarchical structure of codes for this research was between super code/node benefits and its child nodes, such as, advisory and monitoring, iterative and incremental development, frequent definition of tasks and objectives, expose the current situation of work, and frequent checkpoints and deliveries. In our case, super nodes were defined as more general topics arising during the interviews and child nodes were the idiosyncratic opinions given by interviewees regarding a given topic.

In the following sections we discuss the main data gathered from the interviews, identifying patterns and illustrating with excerpts.

\subsection{Preliminary knowledge of Scrum}

Because most students were aware of software design methods, we started by asking if they already had knowledge of Scrum before starting their master thesis, and if they had already used or adopted it in some context. Only six interviewees did not know anything, nor had used Scrum techniques, until they began to be supervised with it during the development of their thesis. Another four of the remaining fifty participants mentioned that they did not use Scrum in an academic

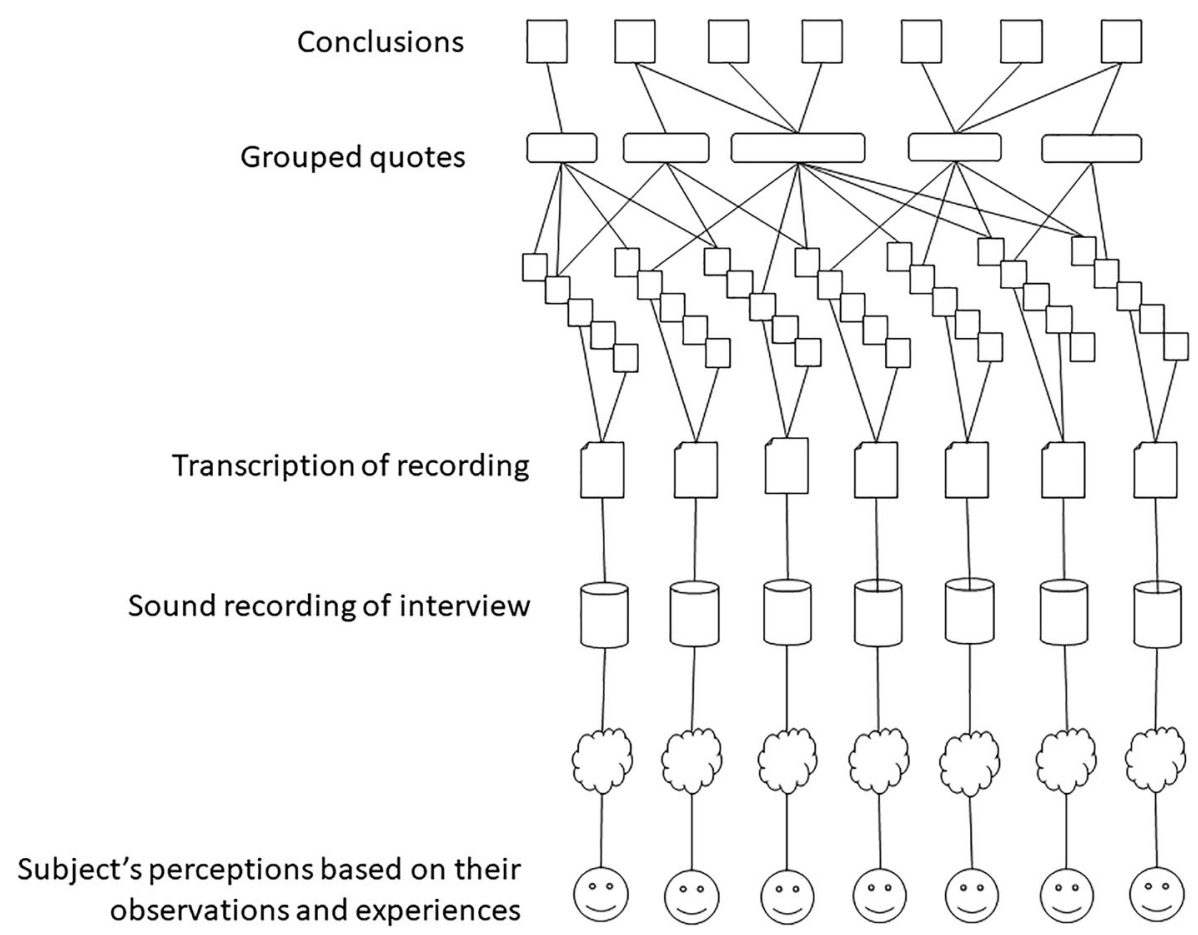

Fig. 3 Coding process based on (Runeson and Höst 2009) 
context, but instead they obtained knowledge about it and used it in professional contexts. The majority of students throughout their academic studies learned Scrum techniques and developed projects in the context of a software development course.

\begin{abstract}
Participant 1: 'My first interaction with Scrum was in a software engineering course where we frequently defined Sprints and tasks. We had several Sprints and in each there were several tasks associated. Each task had an associated state that could be swapped, e.g. if the task had not started or if it was still incomplete. This helped us to plan the following sprints better, considering what needed to be done, which task had more priority, and deciding who was responsible for doing it, thus allowing for a better management of the work.'
\end{abstract}

We asked students that began their master's theses in the 2017/2018 academic year if they had some positive expectations regarding the adoption of Scrum in the context of their master's thesis. Only one student had no expectations regarding the use of Scrum in the development of the master thesis. The rest of the students embraced Scrum as a way to help them be more organized in their work, and expected a more effective monitoring by their supervisor.

Participant 2: 'My expectation was that it was something useful, that would improve my performance with the research work and would not let me accumulate too much backlog.'

\title{
4.2 Application of Scrum in developing the thesis
}

To find out about Scrum roles, meetings, and artefacts, we asked the participants which elements commonly applied in the Scrum methodology were being used in the context of their thesis management and development. Forty-three interviewees said that planning was part of the management process of their master's theses. The interviewees pointed out that this component corresponded to the Sprint Planning meeting in Scrum. Interviewees also mentioned that this operation was connected with their backlog, defined as a list of tasks that they committed to do during a Sprint. Forty-two interviewees stated that during guidance and management processes a backlog was updated across several Sprints. During the planning stage, participants typically discussed the next steps and tasks to be addressed in the context of their thesis. Likewise, they identified the definition of tasks as a negotiation between the supervisor and themselves about what should be done next in order to establish the next Sprint. Interviewees also mentioned that planning was based on what was accomplished in the previous Sprint, on the review of that Sprint, and on tasks in the backlog that had not been assigned to a Sprint.

Participant 3: 'There was a component of planning in which the supervisor always provided me with an idea of what I should be doing, for example, researching about related work in order to have a perspective of what I should 
do to progress. This helped me plan the following work and figure out which tasks should I focus on.'

Participant 4: 'The planning part was defined with the supervisor and we always tried to reach an agreement based on what was supposed to be done in the following sprints. We also discussed what were the tasks to deal with immediately, what tasks could wait for the next sprint, and analyze things that were blocked, for example, due to the waiting for interviews or answers from someone.

Regarding the backlog, participants stated that this component corresponded to the Sprint Backlog commonly used in the Scrum framework for software development. Interviewees also revealed that it was very positive to have a Sprint Backlog during the development of the thesis because any new ideas could be written down in the backlog, to be discussed with the supervisor in the next meeting. Participants also said that having a backlog with tasks allocated to a Sprint allowed them to have more focus on that Sprint, and thus avoid forgetting about what was agreed.

Participant 5: 'Every time we remembered a new thing, a new idea that could be implemented in the context of the thesis, we immediately wrote it down in the backlog kept on Trello. Ideas and tasks were present in the backlog and then these tasks and ideas were attributed to specific Sprints when we thought it was a good time to work on them. I think this was quite important in terms of organization.'

Regarding the review stage in Scrum, thirty-seven interviewees mentioned that review was present in the method used for the management of their master thesis. They also said that the review was performed based on the tasks in the backlog. They logged the tasks that were "completed", those that were "work in progress" and those that were still "to be done", and explained what was accomplished during the Sprint. Then, usually, the supervisor would ask students specific questions in order to check if the goals defined previously had been met, if students really accomplished the tasks they committed to perform during a Sprint, and if any task needed to be addressed again in the next Sprint, in case the objectives had not been reached.

Participant 6: 'The review was based on the tasks that were labelled "done", "doing" and "to-do" in that Sprint backlog, and basically consisted in receiving feedback on what was done; but the supervisor was not limited to just assessing what was done, he would ask what your "definition of done" was, and I would have to explain and get further questions. It is interesting that, in addition to show trust in me, the supervisor would pose questions in order for me to question myself, and allowing him to see if I had indeed responded and understood what was necessary. We sometimes decided that it was better to perform the tasks again in order to really understand some of the issues and topics related to the research. So, the review was not just to assess the tasks and get an "okay" for everyone, the supervisor effectively asked if I had understood everything and if it was all clear.' 
In retrospective, only seventeen interviewees stated that this component was present in the management of their master's thesis. Participants noted that during group meetings they exposed the difficulties that arose during the development of the work, and explained how they overcame the problems, after trying with the help of the supervisor and with the suggestions of other colleagues. This was very positive, since it allowed them to share knowledge regarding the issues that surfaced during the development of the research, and pointed out ways to overcome or avoid them, since this process was a learning experience based on issues, mistakes and solutions. Sometimes they mentioned another key benefit of the retrospective stage: understanding the reasons why a task had not been performed during the Sprint.

Participant 7: 'What I felt was that, in the next meeting, we talked freely about the work I had done and the status of the thesis. There was always a lot of feedback from the supervisor and from my colleagues, trying to help improve my work or redirect it in the right direction. In my case I had many undecisive moments, even in the early stage of data gathering (...) I was in doubt as to what to do to enrich my thesis more, and the retrospective stage helped map the problems. I often ended up talking about what had been my week with all my difficulties (...) and I often managed to redirect my work, to improve it, and to get the results I wanted with the help of the supervisor. So, I think that the three stages are important. But this also depends on how you communicate your topics and issues.'

After asking the students about Scrum stages and artefacts commonly used during the development of their master theses, we questioned them if any of the activities was more important or was more relevant during the development of the research work. Nineteen interviewees stated that, in their point of view, no component stood out in relation to the others. Nine interviewees said that all the activities during the development of the master's theses were relevant, and that the combination of these was very important, without highlighting a specific one. Participants mentioned that all the components of the Scrum framework are connected to each other and that there is a natural flow and functional relationship between them.

Participant 8: 'I think it works as a whole. If you do not have the review stage then the planning stage loses importance, because you will not review the tasks planned previously and you will not know if the expected goals were achieved. If you do not have the backlog stage, which shows what to be done next, then the planning stage loses importance, because you are planning based on the present, and you do not know what you have missed before and what you should do after. I think the parts work as a whole and if you pay attention to one Scrum component only the approach will not have the same effect, missing the play among the various parts.' 
Eight interviewees stated that the the Sprint was the most relevant element of the Scrum methodology applied during the supervision process. These participants mentioned that a Sprint implies having frequent checkpoints, namely the need to focus on a specific task during a fixed period of time, having several opportunities to show the current situation of the work, receiving frequent feedback, performing planning and discussion of tasks, and keeping a steady pace. Participants also noted that, due to master theses being developed over a very long period of time, many students developed the (bad) habit of working harder in the latter stages thus neglecting the earlier stages of work. This is not possible with Sprints, since these lead to the completion of the work incrementally and gradually.

Participant 9: 'We had a backlog from the beginning, but we did not know all the tasks that we were supposed to do. As we were going through Sprints, we were defining what the next tasks would be. It was not pre-programmed as in the Waterfall method, we did not list everything to be done during the thesis process, we did it gradually. We were developing small parts of the thesis, the supervisor would advise us to structure the work and our thoughts by means of small scientific articles, as these would turn out to be small "chunks" within the larger thesis. We did that over time with the artefacts produced in the Sprints.'

Seven interviewees mentioned that the most important element of the Scrum framework was the backlog. Participants pointed out that having a backlog allowed them to have missed tasks available to be consulted together by student and supervisor at any time. Participants also said that the backlog was a great starting point for the communication between student and supervisor, serving as a basis for discussing the tasks performed in Sprints.

Participant 10:'(...) if you have a good backlog for each sprint, even if you do not have a product backlog, this is very important, because you have an idea of the instructions given by the supervisor; the same applies to problem solving as it enables to review important points to be developed during the Sprint. Having this kind of organization, in my opinion, is the main success factor for the development of the thesis, namely, having a backlog organized.'

Other seven interviewees stated that forward planning was the most important aspect in the development of their master thesis, as the main focus of the group meetings, and setting the next steps to be performed in a Sprint was always part of the discussion with the supervisor.

Participant 11: 'I think that, if I had to choose, the most important operational factor that makes students finish a thesis is the planning stage, that is where you better define with the supervisor the work and the relevant steps ahead. I think many theses do not reach the end because of bad planning, or because you look at the eight months of the thesis and then realize that the first month is just for the preliminary work, the second month is just for defining the problem, and so on... this 
leads to students not finishing the thesis due to constant delays; so, I would say that flexible planning is the most important factor.'

\subsection{Group meetings}

After assessing the knowledge about the elements of the Scrum framework present in the thesis supervision/management processes, we also asked students if any of these elements were a part of group meetings. Forty-four interviewees reported having group meetings, usually setting the beginning and end of a Sprint, which generally lasted for fifteen days. They mentioned that these meetings were about planning and reviewing of the work done. Typically, the supervisor would bring together all students in the same space for a group meeting.

Participant 12: 'We have a "thesis group" with students "belonging" to the same supervisor, and every 15 days these students gather in a room for a Sprint meeting. Here the students explain, one by one, the work done in those 15 days, the results obtained, the conclusions drawn, and what to enter in the backlog for the next Sprint.'

\subsection{Overall benefits}

To reach a more global stance, we asked the students what the overall benefits of the adoption of the Scrum framework in the management process of their thesis were. In what concerns group meetings, when the supervisor joined all students together, thirtynine interviewees mentioned that it was very beneficial as an opportunity to present and expose to the supervisor the status of the work, but also to share views with others in the group. Thirty-eight participants mentioned that in this way they could obtain feedback in relation to work done in the Sprint and check if something needed to be improved, and then discuss the next steps with the supervisor. Participants also observed that Sprints were useful because they had frequent checkpoints, deadlines and deliveries, and entailed a frequent definition of tasks and objectives (identified by forty-four interviewees). These frequent updates also allowed for a more sustained monitoring by the supervisor; an important aspect referred by forty students.

A benefit arising from frequent feedback, continuous monitoring and constant updates was also pointed out by twenty-nine interviewees, indicating this as a great help to check on progress, i.e., with the feedback received and the ongoing discussion about the next steps, the students and the supervisor would make sure the work was progressing towards the desired results.

Participant 13: 'Another advantage of these shorter cycles is the continuous feedback that you receive in order to check on the master thesis (the product). While the other colleagues, not using the Scrum framework, received feedback in later stages of the work, sometimes with great difficulty to progress because of short deadlines, in our case, the gradual and flexible process was an advantage. The corrections that we had to make were small, because the tasks were 
distributed over time. With these frequent iterations, the supervisor was able to follow our work and suggest corrections as deemed necessary.'

Twenty-two interviewees clearly stated that the review component and the Sprints allowed for an earlier identification of issues. The frequent presentation of the work, and the discussion between student and supervisor, led to an early assessment of difficulties and problems. This triggered positive feedback from the supervisor to unlock many situations. Within the group meetings there was enough evidence of knowledge sharing and problem solving concerning the progress of several students, with interesting accounts of how they solved these issues, alone or with the help of the supervisor.

Participant 14: 'The Scrum method itself indicates that we are not supposed to deliver a final thesis product in two weeks but that we must have something produced to review and change according to an evolving and timely plan. This means that we should not manage things according to a distant deadline, and later realize that the work done was not right. Instead of falling into this situation, we chose to have Sprints and a bi-weekly follow-up, to prevent the issues and errors from becoming too big.'

Since meetings were held with all the students guided by the same supervisor, fourteen interviewees said that each meeting was an opportunity to compare the status and situation of their work with that of the other students. This enabled them to understand whether they were progressing, and check if they needed to change their performance. Thirty-eight participants also said that these group meetings were a good way to exchange experiences, to learn from the questions of other colleagues and to see how other colleagues had solved specific problems.

Another benefit, exposed by forty-three interviewees, was the incremental and iterative nature of the work. The participants stated that, with the bi-weekly frequency of meetings, these were taken as checkpoints or deadlines, since there was a high commitment to perform the tasks set during the planning phase of the group meetings, also because this made the students more motivated to achieve the goals set at the beginning of the Sprint. Other positive aspects were globally pointed out by students: a feeling of responsibility, the accomplishment of tasks and deadlines, empowerment and definition of next steps, the division of a large work into smaller parts, and avoiding to stay behind schedule.

Participant 15: 'This method helps you transform a large problem, such as a master's thesis endeavor, into smaller chunks. When you start the thesis, you do not know what you have to do, and therefore this method helps you handle smaller problems that you can solve. It helps you prioritize things, you know that for 15 days you can do 5 tasks, so by considering the time you can really dedicate to the thesis the tasks become easier. Also, because you know that at the end of those 15 days you will have to present some structured work.'

A more affective benefit, referred by the participants, was the pressure felt during group meetings and Sprint work. Since there was a high commitment to do the tasks planned 
at the beginning of a Sprint, with the review and planning made in a group meeting, there was also a healthy competition among all, in the sense that nobody wanted to fail, and all students had to show the work to the supervisor and the other colleagues. Only six interviewees felt that this component was negative, because they did not appreciate the judgements made from other colleagues, and it did not help to motivate them. On the other hand, thirty-two interviewees stated that this pressure was positive, since it was a welcome factor to drive them to deliver their work on time.

Participant 16: 'This can be seen both as positive and negative; I see it as positive. I mean the pressure and responsibility laid on a student who is making the thesis, to effectively deliver it on time; this for me was very important. It works like in any university course, where we know that in the end we have an exam, and if we do not study we will not pass. With the thesis, there is so much time for completion that, sometimes, if nobody asks how things are, and if there is no pressure, you end up relaxing... and in the end, when the final deadline is near, you will want to rush everything and you are bound to fail. I think that Scrum is very important in keeping a continuous track of the work; you need to have all these checkpoints to apply pressure on yourself and effectively progress.'

In addition, participants identified structure (pointed out in fifteen interviews) and organization (pointed out in thirty-one interviews) as extra benefits. Interviewees stated that Scrum imposed a structure, which made them better prepared to organize and plan the work in various Sprints.

Participant 17: 'The agile part of the method allows you to change what you want to do. If you followed a stricter method you could get to a point where you would have to define everything in a rigid way. So, while Scrum allows you to explore alternative paths, it gives you the flexibility to change things when necessary; it also gives you a robust structure to develop a thesis under the constant monitoring of the supervisor.'

By doing organized work over a certain length of time, within the limits stipulated for completion of the thesis, and in an incremental way, participants were able to effectively deliver and complete thesis work within the expected time. It was also pointed out by thirty-five interviewees that this method was a great mechanism to conciliate the work on the thesis with the work related to ongoing courses, and this was something important since students tend to pay more attention to tasks near important dates, such as marked assignments and exams, and with this method they were able to focus on both the thesis and the other academic tasks.

\section{Discussion of results}

In this section we discuss our findings, alongside the results of other studies presented in Section 2, to assess advantages, benefits, practices, and the relationship between the use of agile methods and the success of projects. The analysis of the participants' 
experiences, concerning the adoption of Scrum methods in the management of their master's thesis, allowed us to have a better understanding of the benefits of agile practices for academic projects.

Our findings are in line with the results obtained by Mariz et al. (2010), showing a positive correlation of the methods used in the success of a software development project, and the success of an academic thesis project, whenever the Scrum framework is used. It was confirmed that, with frequent meetings and a high commitment to the tasks discussed in the planning phase, the agile methodology becomes a relevant factor in the successful development of a master thesis. Also, according to Solinski and Petersen (2016), the most significant benefits of adopting agile methods are knowledge, learning, feedback, and confidence. According to our findings, we can map these benefits to the evidence given by students, specifically during the review phase and the exchange of experiences in group meetings.

Regarding the practices, it is widely accepted that agile processes with few rigid development practices and balanced processes allow to achieve a higher number of benefits' (Solinski and Petersen 2016). The practices we identified are: iteration, planning, meeting, iteration review and retrospective, face-to-face communication, small self-organizing cross-functional teams, frequent planning/reporting, and prioritized list of requirements. However, in what concerns the practice of small selforganizing teams, and considering that a thesis is rather individual, as stated by the interviewees, the key stakeholders are the individual student and the supervisor, and therefore we cannot map this practice to academic theses projects.

Concerning the prioritized list of requirements, we also cannot map this practice to our results, since participants only developed a generic backlog of tasks they were supposed to implement in a Sprint, or tasks that had not yet been allocated to a Sprint. Interviewees clearly stated that all tasks were planned to perform in a Sprint, and there was a matching responsibility to complete those tasks, but they did not refer any "priorities" being discussed during planning. However, other practices such as the iteration planning meeting, iteration review, frequent planning/reporting, and face-toface communication, are present in the thesis management process, according to the interviewees.

According to Rover et al. (2014), Sprints and meetings between the stakeholders foster communication. The benefits originating from these practices are teamwork, product quality, customer focus and iterative development. Benefits such as teamwork were not referred by students since the context of the work (thesis) is associated with an individual performer (student). Product quality was also not referred by students as a benefit of the adoption of Scrum in the context of the development of the master's thesis, because the quality of a thesis is assessed at a later stage by an academic committee, and thus not compatible with this model. Regarding customer focus, it is held that each Sprint involves face-to-face communication, feedback, and collaboration with the customer (Rover et al. 2014). In the academic context there is no communication with a "customer", but instead there is communication between the student and the supervisor at the end of each Sprint, involving face-to-face communication and the necessary feedback to plan and review the work. Regarding the iterative development, Rover et al. (2014) state that 'bi-weekly meetings kept students accountable and motivated them to spread work throughout the semester', which was also reported by 
the participants in our study as a positive factor towards delivering the master's thesis within the stipulated time.

Begel and Nagappan (2007) highlight the top benefits of agile methods in order to form a ranking of common benefits. The top three benefits perceived by participants were: improved communication, quick releases and fast response to change (flexibility of design). Regarding these benefits, the one that we have not yet discussed in this section is "flexibility of design". We did not present it as a benefit for the management of master's theses development because it was only mentioned as a positive aspect by eight interviewees, and therefore we cannot infer that this is a general benefit.

The results presented by Mahnic and Rozanc (2012) also show similarities between students and software developers regarding the practices that lead to the success of a project. Both agree that the two most important success factors are teamwork and communication among team members, as well as good communication with the Product Owner. These factors were not mentioned by the interviewees, since more than half of them refer that "Scrum roles" do not make sense in the development of a master thesis, again because in the academic context thesis development is an individual process. The only roles that may be identified and make sense are those of student and supervisor.

\section{Conclusion}

This study highlighted the value of several Scrum events in the development of academic theses: Sprint Planning meeting, Sprint Review meeting, frequent work deliveries, feedback and collaboration. Moreover, regarding the insufficient knowledge transmission, participants pointed that having group meetings was an opportunity to follow-up on the work of other students, learn with their ideas and developments, and learn from their mistakes. However, Scrum has specific roles, such as Product Owner, Scrum Master and Team Member, which have specific responsibilities that are not appropriate for an academic context such as thesis development. So, to answer our preliminary question: is the Scrum project management framework applicable to theses management? To a certain extent, yes. In what concerns our main research objective, we found that the adoption of Scrum and many of its methods can positively influence the success of a master thesis development process, thus overcoming the issues previously stated by students who were not satisfied with the supervision. In essence, the adoption of Scrum may be a way to foster communication and organization between students and supervisors, generating positive feedback, and improving the work in progress.

Looking back, considering that we could not find any previous study on the subject of Scrum applied to the supervision of theses, our research had to examine the experiences and use of the Scrum framework by a small group of students in a specific institution, spanning a few years. Based on qualitative data gathered through interviews we were able to find out which practices of Scrum and agile were more appropriate, according to the interviewees, and which benefits were generated by them. We also compared our results with the work of other researchers in somehow different contexts. However, a more systematic and in-depth analysis of the implementation of Scrum in 
the academic context is needed, considering the subjective experiences of participants, but advancing beyond an exploratory research endeavor.

Acknowledgements This scientific research project was carried out following ethical guidelines accepted by IST (Instituto Superior Técnico), i.e., acknowledging the social value of the work; its scientific validity; a fair subject selection; a favorable risk/benefit ratio for the subjects; assurance of informed consent; and anonymity for all enrolled subjects. These principles were applied to data collection and treatment, and overall academic community needs and values were considered along with those of the individual.

The authors would like to thank the interviewees who participated in this case study, acknowledging their interest and the time dedicated to this research.

Authors' contributions All authors contributed evenly to the paper.

Funding No funding (the research was developed in the context of a master thesis).

Data availability All the data used in the paper was collected by the authors.

\section{Compliance with ethical standards}

Conflict of interest One of the authors was the supervisor of the master students interviewed for the paper.

Code availability We did not use any code in this paper.

Open Data Data collection for this study was undertaken in agreement with IST (Instituto Superior Técnico). All opinions presented in this manuscript belong to the authors alone, and not any institution to which they are or were affiliated. The raw data cannot be made public for anonymity reasons. Also, the interviews cannot be disclosed according to the research method followed and because interviewees were told that the data was going to be studied altogether and not on a case-by-case basis.

\section{References}

Adu, P. (2016). Perfecting the art of qualitative coding. Retrieved from https://www.qsrinternational.com/ nvivo-qualitative-data-analysis-software/resources/blog/perfecting-the-art-of-qualitative-coding.

Baxter, P., \& Jack, S. (2008). Qualitative case study methodology: Study design and implementation for novice researchers. The Qualitative Report, 13(4), 544-559.

Begel, A., \& Nagappan, N. (2007). Usage and perceptions of agile software development in an industrial context: An exploratory study. In Empirical Software Engineering and Measurement, (ESEM 2007), pp. 255-264, IEEE.

Benbasat, I., Goldstein, D. K., \& Mead, M. (1987). The case research strategy in studies of information systems. MIS Quarterly, 11(3), 369-386.

Broman, D. (2015). A process for student group supervision. Technical report, KTH Royal Institute of Technology.

Dinis-Carvalho, J., Ferreira, A., Barbosa, C., Lopes, C., Macedo, H., \& Tereso, P. (2018). Effectiveness of scrum in project-based learning: Students view. Paper presented at the International Conference on Innovation, Engineering and Entrepreneurship. https://doi.org/10.1007/978-3-319-91334-6_154.

Hans, R. T. (2017). Work in progress - the impact of the student Scrum master on quality and delivery time on students' projects. In Learning and Teaching in Computing and Engineering (LaTICE 2017), pp. 87-90. IEEE.

Hicks, M., \& Foster, J. S. (2010). Score: Agile research group management. Communications of the ACM, $53(10), 30-31$. 
Hilal, A. H., \& Saleh, A. (2013). Using NVivo for data analysis in qualitative research. International Interdisciplinary Journal of Education 2(2):181-186.

Kudikyala, U. K., \& Dulhare, U. M. (2015). Using scrum and wikis to manage student major projects. In MOOCs, Innovation and Technology in Education (MITE 2015), pp. 15-20, IEEE.

Mahnic, V., \& Rozanc, I. (2012). Students' perceptions of Scrum practices. In Proceedings of the 35th International Convention MIPRO 2012, pp. 1178-1183, IEEE.

Mariz, L., Souza, M. R., César, A., França, C., \& Silva, F. Q. B. (2010). An empirical study on the relationship between the use of agile practices and the success of software projects that use Scrum. In Brazilian Symposium on Software Engineering (SBES 2010), pp. 110-117, IEEE.

Overhage, S., Schlauderer, S., Birkmeier, D., \& Miller, J. (2011). What makes IT personnel adopt scrum? A framework of drivers and inhibitors to developer acceptance. In 44th Hawaii International Conference on System Sciences (HICSS 2011), IEEE.

Robson, C., \& McCartan, K. (2016). Real world research. New York: Wiley.

Rover, D., Ullerich, C., Scheel, R., Wegter, J., \& Whipple, C. (2014). Advantages of agile methodologies for software and product development in a capstone design project. In Frontiers in Education Conference (FIE 2014), pp. 1-9, IEEE.

Runeson, P., \& Höst, M. (2009). Guidelines for conducting and reporting case study research in software engineering. Empirical Software Engineering, 14(2), 131-164.

Saldaña, J. (2015). The coding manual for qualitative researchers. London: Sage publications.

Solinski, A., \& Petersen, K. (2016). Prioritizing agile benefits and limitations in relation to practice usage. Software Quality Journal, 24(2), 447-482.

Sutherland, J. (2014). Scrum: The art of doing twice the work in half the time. New York: Crown Business.

Sutherland, J., \& Schwaber, K. (2017). The definitive guide to Scrum: The rules of the game. Retrieved from: https://www.scrumguides.org/docs/scrumguide/v2017/2017-Scrum-Guide-US.pdf.

Turner III, D. W. (2010). Qualitative interview design: A practical guide for novice investigators. The Qualitative Report, 15(3), 754-760.

Yin, R. K. (2017). Case study research and applications: Design and methods. London: Sage publications.

Publisher's note Springer Nature remains neutral with regard to jurisdictional claims in published maps and institutional affiliations. 